to confront the epidemic head-on. Now that a growing number of them are facing the issue, we cannot afford Western leaders to go into denial about how much it is going to cost to fix the problem. For the first time, the world is united in spirit behind an ambitious plan to curb the spread of HIV. The unprecedented declaration accepted by 185 states at last month's special UN General Assembly session on AIDS is compelling evidence of a new willingness by the hardest-hit countries in Africa and Asia to step up their prevention programmes and to make the necessary improvements in health infrastructure.

We, the authors of this Commentary, collectively have more than 150 years' experience of HIV/AIDS, as scientists, clinicians or public-health experts. We believe that the Global AIDS Fund, if properly financed and managed, represents our best chance to stem the epidemic. How the fund is managed and run needs to be determined, but it must not become a turf war between development agencies and stakeholders. There is room for everyone's ideas to be included.

Decisive action by the G8 nations is crucial in determining whether the fund is successfully launched this year on the scale required. The success of the rich, industrialized nations is inextricably linked to the success of the developing nations. This is why we hope that the G8 countries will rise to the occasion and find ways to finance the fund to accomplish its mission. Such action will not only be a mark of true leadership, but also of humanity in its highest form.

1. Sachs, J. D. Nature Med. 7, 521-523 (2001).

2. Schwartländer, B. et al. Science 292, 2434-2436 (2001).

\title{
Success hinges on support for treatment
}

$\mathrm{H}$ IV prevention and treatment are inseparable. One big debate that never materialized during the UN General Assembly meeting on AIDS last month (see Nature 411, 984; 2001) was about priorities for the Global AIDS Fund, particularly how to allocate funds to prevention compared with those for improvements to publichealth infrastructure and access to treatment with anti-HIV drugs. Most AIDS experts endorse the idea that prevention and treatment are crucially linked, and the authors of a policy forum in Science (292, 2434-2436; 2001) estimate that the split should be roughly 50/50. Unfortunately, not all government and private development agencies agree, nor do some high-ranking Western officials.

The overwhelming majority of Africans, of course, want treatment; the question is not 'if' but 'when'. "Don't even ask us," said one African delegate. "The answer is yes, yes, yes and yes." You can ask the same question of any young man or woman on the streets of Soweto or Lusaka and get the same answer.

Any debate on prevention versus treatment would not have been possible even a year ago because of the prohibitively high cost of combination anti-retroviral therapy. Since then, drug companies have discounted the cost of these medicines for the leastdeveloped countries, sometimes by as much as $90 \%$. So far, 58 nations have purchased HIV/AIDS drugs at preferential prices, bringing the cost of treating HIV closer to that of treating chronic conditions such as type-2 diabetes and high blood pressure.

Prevention and care are synergistic. Attempts to prioritize one at the expense of

\section{here is little incentive to get tested for HIV if there is no treatment.}

the other are morally indefensible, a denial of a fundamental human right, and just plain bad public health. The main argument for focusing on prevention rather than treatment is that it is more cost-effective when funds are limited. This masks the mistaken but still widely held view in the West that treatment in poor countries cannot be funded, even with discounted drug prices, because of the lack of basic health-care infrastructure (trained doctors and nurses, hospitals, clinics, labs and equipment).

Yet considerable infrastructure exists in countries such as South Africa, Kenya and Zimbabwe. Where there is political will, infrastructure can be upgraded on a crash basis. Human ingenuity to create temporary structures to do the job effectively should not be underestimated; many Western hospitals boast trailers and temporary buildings yet deliver world-class medical care. Certainly, money is needed for infrastructure, but a little goes a long way in Africa.

Another myth is that Africans will be unable to follow complex drug regimens, leading to the development of resistant virus that could be transmitted. On the contrary, studies in Africa, especially in Uganda and Senegal, show that compliance with drug regimens where there is patient education is as good as in New York City. In any event, regimens are nowadays much more simple.

A third myth is that the standard of HIV care would be suboptimal, so it should not be attempted. This hypocritical view overlooks the beginnings of HIV treatment in the West (monotherapy, then bi-therapy, then triple therapy), as doctors and patients learned as they went along. It was distressing to hear this argument advanced by a few African officials after the UN meeting. It also sets an impossibly high standard for expanded access to HIV care for the vast majority of Africans who are poor, unemployed or without health insurance.

Finally, treatment with anti-retroviral drugs helps prevention efforts. There is little incentive for people to get tested for HIV if there is no treatment. An HIV-negative result is a prime opportunity to deliver prevention messages; for a positive test the prospect of treatment increases awareness, removes stigma and encourages safe practices - all of which reduce the rate of new HIV infections.

There is now unstoppable momentum to address the challenge of how to expand access to HIV care and treatment in low- and middle-income countries. For the leastdeveloped nations, including all of sub-Saharan Africa, heavily discounted drugs are available. For middle-income countries, such as Brazil, continued local manufacture of antiHIV drugs or importing of generic versions is to be allowed until the crisis is controlled.

The UN meeting was intended to intensify national and international action, and to mobilize the billions of dollars needed to combat the epidemic. It was successful in the first respect, particularly in terms of commitments made to specific prevention targets. But the breakthrough was the agreement that the Global AIDS Fund should also cover treatment. We hope that the G8 leaders will respond not just with more money but by mandating the fund to tackle treatment. Corresponding author: Peter Hale, Institut Necker, Faculté de Médecine Necker-Enfants Malades, 156 Rue de Vaugirard, 75015 Paris, France. Co-authors: Malegapuru William Makgoba (President, Medical Research Council of South Africa); Michael H. Merson (Professor and Dean of Public Health, Yale University School of Medicine); Thomas C. Quinn (Professor of Medicine and International Health, Johns Hopkins University, Baltimore); Douglas D. Richman (University of California, San Diego); Stefano Vella (President, International AIDS Society, Istituto Superiore di Sanità, Rome); Fred Wabwire-Mangen (Director, Institute of Public Health, Makerere University,

Uganda); Simon Wain-Hobson (Institut Pasteur, Paris); Robin A. Weiss (University College London).

The authors thank Helene Gayle (CDC, Atlanta) for discussions and suggestions, and Bernard Schwartländer (UNAIDS) and R. P. Eddy (UN Foundation) for fact-checking. 